Bulletin de la Société Royale des Sciences de Liège, Vol. 85, 2016, p. 140 - 152

\title{
Multi-objective optimization to have optimal utilization from renewable energy sources in building with zero energy
}

\author{
Mansoureh SAFAKAR ${ }^{1, *}$-Masoud OMIDVAR ${ }^{2}$-Maziar YAZDANI ${ }^{3}$ \\ ${ }^{1}$ Islamic Azad University, Zahedan branch, College of engineering, Department of electrical engineering, Zahedan, \\ Iran \\ ${ }^{2}$ Sama technical and vocational training college, Islamic Azad University, Zahedan branch, Zahedan, Iran \\ ${ }^{3}$ Islamic Azad University, Science and research branch, College of engineering, Department of nuclear engineering, \\ Tehran, Iran
}

\begin{abstract}
By reducing fossil fuel resources, power system operators have interested in renewable energy sources. On the other hand, energy consumption in buildings is included about 40 percent of all energy used in the world. Thus, the researchers have always been seeking a solution to reduce power consumption in the building. This has been led to introduction of the concept of zero-energy buildings. Zero energy buildings refers to buildings that have zero or positive energy consumption in one year. The plane of building houses with zero energy consumption is based on using the household sector from renewable energies. In this study, solar energy and wind energy among renewable sources are selected to meet the power requirements in buildings. The output power level of renewable sources is uncertain and is constantly changing due to the fluctuating nature of wind speed and solar radiation .So in this study, first, the method is provided to forecast output power sources by the neural network algorithm. To utilize a building in dependently, renewable resources should be available with sufficient capacity and energy storage such as batteries, should be available to cover the time periods when renewable resources are not able to produce power. Genetic algorithm will be used to solve the optimization problem. Therefore, in this study, considering to the cost and the least certain amount of load as objective functions system, production planning and consumption in buildings are implemented based on the DGs as a multi-function and the optimized capacity of photovoltaic panels and wind turbines will be determined.
\end{abstract}

Keywords: zero-energy building, genetic algorithms, wind energy, photovoltaic energy, energy storage

\section{INTRODUCTION}

With rising energy costs in most places in the world in the 1970s and 1980s, engineers began to build houses with low energy consumption. But still building houses with zero energy consumption is in the field of studies. With increasing

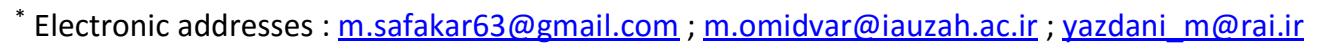




\section{Bulletin de la Société Royale des Sciences de Liège, Vol. 85, 2016, p. 140 - 152}

government attention to this issue in the United States according to the law passed in 2007 to support the creation of buildings with zero net energy consumption, half of US commercial buildings by 2040 and commercial buildings by 2050, their net energy consumption should be zero .In Europe, it was decided in 2010 , zero energy consumption will be applied to public buildings and buildings belonging to officials by 2018 and then will be applied to all new buildings by 2020.In Iran in 1370 with the approval of article 19 by the Council of Ministers, a major step was taken in the context of energy savings in buildings and its applying is mandatory for government buildings since 1384.Implementation of this topic increases the cost of building up to $5 \%$ and decreases the heating and cooling capacity of systems up to $40 \%$ [1].

In general, zero energy houses are referred to houses which are away from the power grid (not connected to the network) and are supplied by using renewable energy sources like solar and wind. Something that is remarkable about the zero houses, is the supplying of energy use on cloudy and rainy days which this problem has been solved by storing energy on other days .But the costs of energy saving resources are high and there for the plan of houses with zero net energy consumption is more prevalent that there is interaction with the network and, if necessary, energy is purchased from the network. Also, the energy surplus sold to network at other times and finally, the annual net energy consumption is zero. .In general, studies have been conducted in the context of zero energy buildings that here have been referred briefly to some of them. In [2], a study has been conducted on the impact of weather conditions on the use of zero energy buildings in Saudi Arabia. This study pointed out that the household sector in the country consume 52 percent of total production capacity of the network. The main focus of this study is on the impact of weather conditions and the possibility of using technology with zero energy buildings in the country. In [3], in this study an optimized issue based on genetic algorithm is used to determine the optimal structure of renewable energy sources. In this study, the use of renewable sources, and also distributed generation diesel generator have been studied and economic benefits and their impact on reducing environmental pollution have been studied .Results showed that the reduction in the costs of system operations and environmental pollution is possible by the use of renewable energy sources in the structure of zero-energy buildings. In reference [4], possible solutions are studied to design zero-energy buildings in the UK. In this study, the amount of solar radiation and productivity of photovoltaic systems and wind systems can be achieved after obtaining weather information. Then the optimal structure has been implemented to supply power by the help of renewable sources. In [5] two energy systems are introduced based on residential buildings with zero energy and have been designed with different weather conditions for the cities of Shanghai and Madrid. The first example is an apartment in Shanghai and the second one is designed and built at a university in Madrid. Climatic studies have been conducted related to two regions and the results show that the main difference of these two cities is in their annual moisture. In [6] the possibility of implementation in Southern Europe has been studied, due to weather conditions of these two regions that have high levels of solar radiation, solar panels (thermal and photovoltaic panels) are used as a source of renewable energy. Two simulated models have been used for studies. In reference [7] studies on the feasibility of developing renewable-energy buildings in America are examined. Two renewable systems used in these studies are wind energy and solar thermal systems. In fact, the main objective of the paper is to examine the impact of parameters such as weather, wind and solar sources, energy prices and government incentives on the cost 
and the design of solar thermal system sand wind energy .For this purpose, 5 cities with different climatic conditions were studied in America.

Due to the high operating costs of such a structure and mechanism, the discussion about investment and operation costs will be considered as one of the important constraints. Therefore, in this study, suitable capacity for DGs will be examined the optimum exploitation of the building which will be required to study environmental conditions system and consumption pattern of consumer.

This article has been prepared in five sections as follows .In the second part, after reviewing the concept of smart houses, the proposed method will be introduced to determine the resources capacity and production trends of renewable units. Then, the genetic algorithm is discussed to solve the optimization problem in the third section and finally, the simulated results and conclusions are presented in the fourth and fifth sections, respectively.

\section{THE STRUCTURE INTRODUCTION AND THE PROPOSED METHOD}

In a zero-energy buildings, the main objective of supplying the building energy is independently available by using the productive resources. Most of these resources are renewable resources and energy storages will be battery. So, most of the operation of the system is done in a way to optimize the objective functions, including costs. In this study, in order to solve the problem of previous studies, a multi-objective function is used to determine the optimal capacity of productive resources and their production trends during a day. In this paper, three objective functions are considered to evaluate the performance of buildings in various combinations of renewable energy systems: the total cost (TC), carbon dioxide emissions (CDE), index of network interactions (GII). The minimization of total cost (TC) is presented in equation (1) in a year. The total cost is equal to annual operating cost of building Cost $_{\text {operation }}$ ) plus annual investment cost of renewable energy systems $\left(\right.$ Cost $\left._{\text {resi }}\right)$. The carbon dioxide emissions which is obtained from the generation of electricity and bio-fuel generator is presented in equation (2). Carbon dioxide produced by power delivered is calculated by using equation (3). ${ }^{W_{i m}}$ and $W_{e x}$ are the network input and output power, respectively .The amount of carbon dioxide emitted from bio fuels is calculated by using equation (4) [8-10].

$$
\begin{gathered}
\text { Min } T C=\text { Cost }_{\text {resi }}+\text { Cost }_{\text {operation }} \\
\text { Min CDE }=C D E_{\text {ele }}+C D E_{B D G} \\
C D E_{\text {ele }}=\left(W_{\text {min }}-W_{e x}\right) \times c d e_{e l e} \\
C D E_{B D G}=F_{b i o} \times c d e_{b i o}
\end{gathered}
$$

The interaction of building - network which is described in Equation (5) is based on the ratio of net energy output (ie the difference between input and output energy) and the average energy demand of building over a certain period. Indicator of grid interaction (GII) which is shown in equation (5), is defined as the standard deviation of buildingnetwork interaction over a year. This index is used to estimate the average pressure of building on the network and low standard deviation is preferred.

$$
\operatorname{Min} G I I=S T D\left(f_{\text {grid }, i, T}^{\prime}\right)
$$




$$
f_{g r i d, i, T}^{\prime}=\frac{W_{e x, i}-W_{i m, i}}{\int_{t 2}^{t 1} E_{i} d t / T}
$$

Multi-objective optimization problems, can be simplified to an objective optimization using the weighted sum of the 3 objectives as shown in equation (10). The combined purpose $f$ ) is used to evaluate the performance of building energy systems. The sum of $w_{1}, w_{2}$ and $w_{3}$ is equal to 1 .To normalize objectives ,the configuration of similar buildings will be chosen. After removing all renewable energy systems as a standard building (BB ). $T C_{B B}, C D E_{B B}$ and $f_{\text {grid }, i, T, B B}$ are the total cost, carbon dioxide emissions and indicators of network interactions for standard building ,respectively. $T C_{n}, C D E_{n}$ and $f_{\text {grid, }, T, \mathrm{n}}$ are the normalized total cost, normalized carbon dioxide emissions and normalized indicators interaction of network. The smaller combined objective show better performance of building energy systems.

$$
\begin{aligned}
& T C_{n}=\frac{T C}{T C_{B B}} \\
& C D E_{n}=\frac{C D E}{C D E_{B B}} \\
& f_{\text {grid }, i, T, n}=\frac{f_{\text {grid }, i, T}}{f_{\text {grid }, i, T, B B}} \\
& f=w_{1} \times T C_{n}+w_{2} \times C D E_{n}+w_{3} \times f_{\text {grid }, i, T, n}
\end{aligned}
$$

\section{THE COOLING DEMAND}

Building cooling demand $\left(Q_{c}\right)$ is estimated by absorption cooling $\left(Q_{a c}\right)$, and electric cooling $\left(Q_{e c}\right)$ are shown in equation (11).When the cooling load is less than the capacity of absorption cooling $Q_{a c, d e s i g n}$, design),he total cooling load will be covered by cooling absorption (equation (12)). Otherwise, absorption cooling works at its maximum capacity and overload cooling is provided by the electric cooling (equation (13)).In the heat recovery system, heat demand can be expressed by equation (14). Absorption cooling capacity $Q_{a c, d e s i g n}$, design) is selected in accordance with the capacity of bio-fuel generator $\left(Q_{\text {bio, design }}\right.$, design $)$. The efficiency of heat recovery system $\left(\eta_{h r s}\right)$ and the degree of absorption cooling $\left(\mathrm{COP}_{a c, d e s i g n}\right)$ are shown in equation (15) [9].

$$
\begin{gathered}
Q_{c}=Q_{e c}+Q_{a c} \\
Q_{a c}=\left.Q_{c}\right|_{Q_{c}<Q_{a c, d e s i g n}} \\
Q_{a c}=\left.Q_{a c, d e s i g n}\right|_{Q_{c}>Q_{a c, d e s i g n}} \\
Q_{r}=\frac{Q_{a c}}{C O P_{a c}} \\
Q_{a c, d e s i g n}=Q_{b i o, d e s i g n} \times \eta_{h r s} \times C O P_{a c, d e s i g n}
\end{gathered}
$$




\section{ELECTRICITY DISTRIBUTION AND DEMAND}

The balance between the building supply $\left({ }^{W_{\text {sup }} l y}\right)$ and demand $\left(W_{\text {demand }}\right)$ is considered (equation (16)).As is shown in equation (17), the consumption (demand) of electricity in the building is related to two systems: $\mathrm{HVAC}\left(W_{H V A C}\right)$ and other components $\left(W_{\text {other }}\right)$. Electricity supply is provided by $\mathrm{PV}\left(W_{P V}\right)$, wind turbine $\left({ }^{W_{W T}}\right)$ and bio-fuel generator $\left(W_{B D G}\right)$ while the electricity grid $\left(W_{\text {grid }}\right)$ is considered as a storage for surplus power and the cover for the lack of electricity(equation (18)). $W_{\text {other }}$ includes power-lighting consumption, output socket and fuse. In system HVAC, $W_{H V A C}$ is the power consumed by electric cooling $\left(W_{e c}\right)$, pumps $\left({ }^{W}\right.$ pump $)$, cooling tower fans $\left(W_{c t}\right)$ and AHU (air handling unit) ( $\left.W_{f a n}\right)$, as it has been shown in equation (19).

$$
\begin{gathered}
W_{\text {demand }}=W_{\text {sup } p l y} \\
W_{\text {demand }}=W_{H V A C}+W_{\text {other }} \\
W_{\text {supply }}=W_{P V}+W_{W T}+W_{B D G}+W_{g r i d} \\
W_{H V A C}=W_{e c}+W_{p u p m}+W_{c t}+W_{\text {fan }}
\end{gathered}
$$

Power Grid can act as a backup power source and the receiver of building .As is shown in equation (20), actual power required for the building of grid depends on building electricity demand and the production of renewable energy. $W_{\text {grid }}>0$ indicates that the network produces electricity for the building and it means that the building sends surplus power to the grid [8-9].

$$
W_{\text {grid }}=W_{H V A C}+W_{\text {other }}-\left(W_{P V}+W_{W T}+W_{B D G}\right)
$$

Electric cooling model: the electricity consumption of electrical cooling is calculated according to th®OP $P_{e c}$ (equation (21)). Usually slightly less cooling load is achieved in less $C O P_{e c} . C O P_{e c}$ electric cooling changes based on the slight cooling load (PLR ) and an experimental model shown in equation (22) is used [10] in this equation $a=-1.6757$ ، $b=0.3083$ ، $c=3.5093$ and $d=0.853$. These parameters $(a, b$ ، $c$ and $d$ )are obtained 0.9 by model adaptation with cooling data in ZCB.In this study, $\mathrm{COP}_{\mathrm{N}}$ is Normal cooling capacity and its value is 2.4. The temperature of output water fogger $\left(T_{\text {eva out }}\right)$ is set in a way that be $7{ }^{\circ} \mathrm{C}$ in the simulation tests and it is assumed that the temperature of input water condensation $\left(T_{\text {con,in }}\right)$ is different from wet-bulbof cooling towers inlet air $\left(T_{w b, i n}\right)$ $5 \mathrm{~K}$.

$$
W_{e c}=\frac{Q_{e c}}{C O P_{e c}}
$$




$$
\begin{aligned}
& C O P_{e c}=C O P_{N} \times \frac{T_{\text {eva }, \text { out }}}{T_{\text {con }, \text { in }}-T_{\text {eva,out }}} \times \\
& \left(a \times P L R^{3}+b \times P L R^{2}+c \times P L R+d\right) \\
& T_{\text {con,in }}=T_{w b, \text { in }}+5
\end{aligned}
$$

Pump models: Cooling water pumps have constant pumping speed and it is assumed that they are working at given power. Cooling water pumps have variable pumping speed. As is shown in equation (24), power consumption of pumps depends on pressure drop $\left(\Delta p_{c w p}\right)$, flow rate of water $\left(m_{w}\right)$ and pump efficiency $\left(\eta_{c w p}\right)$. As shown in Figure (1) and equation (24), pressure drop of cold water loop (which is equal to the pressure of pumps head) in buildings, is assumed to be linear to the water flow rate $\left(m_{w}\right)$.

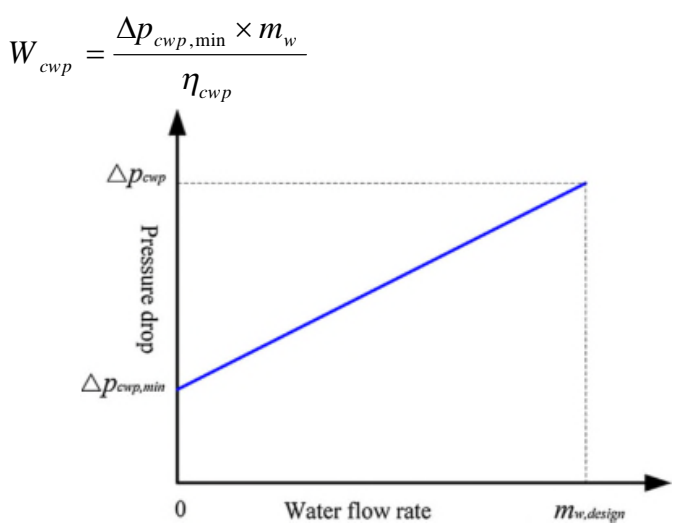

Figure 1: Pressure Drop of chilled water loop

After the introduction of the method, the proposed algorithm has been introduced to solve the optimization problem in the next section of genetic algorithm.

\section{GENETIC ALGORITHM}

\subsection{Chromosome}

Genetic Algorithm works with the coded form of parameters or variables .Strings or a sequence of bits as coded form which is the possible answer ( suitable or not ) to the problem, called chromosome .In fact, the bits in a chromosome play the role of genes in the environment which is shown in Figure 2. ${ }^{i}$ in this figure is the amount of $i_{\text {th }}$ bit.

\begin{tabular}{|l|l|l|l|l|l|}
\hline$c_{1}$ & $c_{2}$ & $c_{3}$ & $\cdots$ & $c_{n-1}$ & $c_{n}$ \\
\hline
\end{tabular}

Figure 2: A chromosome 


\subsection{Population}

Set of chromosomes is called the population. One of the characteristics of genetic algorithms is that instead of focusing on one part of the search space or a chromosome, works on the population of chromosomes. Thus, at each step, algorithm has a population of chromosomes which has the desired properties more than a population of previous step.

\subsection{Fitness value}

Whether the answer is appropriate or not, is measured by the criteria obtained by objective function. The more appropriate answer has a much larger fitness. To increase the chance of answer survival, its possibility is considered by its fitness value. Thus, the chromosome that is more fitted,more likely participate in producing children and more sequences are generated.

\subsection{Intersection operator}

This operator acts on a pair of chromosomes and two chromosomes are randomly broken from one point and moves the parts of two chromosomes. Thus two new chromosome are obtained. The initial chromosomes are called parent chromosomes and chromosomes derived from transposition and mutation are called children chromosomes.

The intersection operator is operated on parent chromosomes by the probability of $P_{c}$. This means that, the transposition is done by the probability of $P_{c}$. The chromosomes have been made of coded form of $x, y, z, w$ variables in Figure (3).

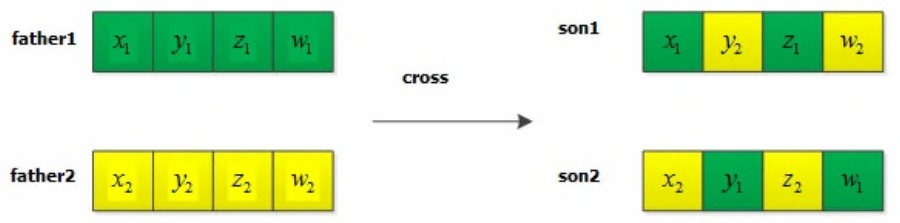

Figure 3: Translocation in chromosomes

\subsection{Uniform combination}

Each new chromosome gene is chosen individually in uniform combination. Each gene is randomly selected from one of the two parents. An example of uniform combination can be observed in Figure 4.

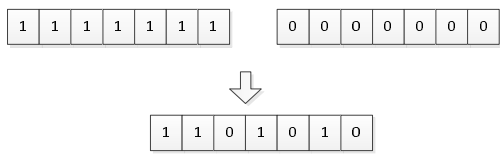

Figure 4: Uniform combination 


\subsection{Mutation operator}

This operator randomly selects a chromosome from a population and make a new chromosome by changing it randomly. Binary mutation is one of the types of mutations that have been used in this study. The operator performance is shown in figure (5).
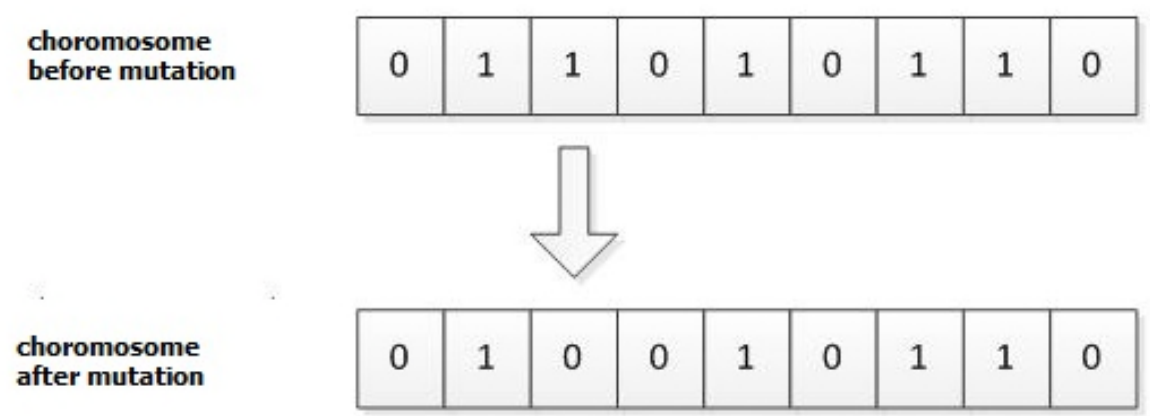

Figure 5: The binary mutation operator

\subsection{Selection operator}

A new population is formed by selection of the number of chromosomes in a population. This choice is a such way that the probability of chromosomes with higher fitness in the final population is more than other chromosomes .Roulette wheel selection method is a method that has been used to select candidates to apply combination and mutation operators .Probability of selection corresponding to each chromosome is calculated based on its fitness. If $f_{k}$ is the fitness value of $k_{\text {th }}$ chromosome, the probability of survival corresponding to that chromosome will be:

$$
P_{k}=\frac{f_{k}}{\sum_{i=1}^{n} f_{i}}
$$

Now, we arrange chromosomes based on $P_{k}$ and $q_{k}$ which is the cumulative value of $P_{k}$ is obtained as follows:

$$
q_{k}=\sum_{i}^{k} P_{i}
$$

\section{SIMULATION AND NUMERICAL STUDIES}

The studied network is a set of 10 houses ,the power of these houses are supplied by manufacturing resources including solar panels, small wind turbines and bio-diesel generator .Studies for system per 24 hours, including planning the production arrangement of units have been conducted based on the required level of load .But studies related to determine the optimal capacity of the resources should be based on annual profiles of electric power consumption in system .Information on the daily load system is provided by Figure (6).On this day, the total network load is $1524 \mathrm{~kW}$ 
and the peak load is $140 \mathrm{~kW}$ and occurred at $4 \mathrm{pm}$. It is worth noting that heating and cooling loads are supplied by the electric power in grid.

To take advantage of the system and determine the optimal capacity of DG, the range of production and its utilization should be considered . Thus, first the cost of investment, operation and maintenance and replacement of these units are given in Table 1.The costs are expressed in terms of dollars per $\mathrm{kW}$.

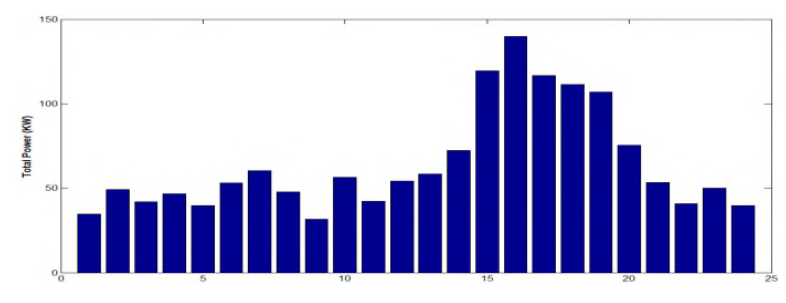

Figure 6: The curve of load consumption within 24 hours

\begin{tabular}{|c|c|c|c|c|}
\hline & diesel generator & photovoltaic system & wind unit & battery \\
\hline Investment cost & 45 & 70 & 100 & 48 \\
\hline Replacement cost & 31 & 52 & 75 & 0.04 \\
\hline Maintenance cost & 0.75 & 0.5 & 1 & 0 \\
\hline Fuel cost & 0.08 & 0 & 0 & 0 \\
\hline Startup Cost & 0.35 & 0 & 0 & 0 \\
\hline
\end{tabular}

The output power of $P V$ and the output power of wind units are related to the radiation of sunlight and wind speed respectively and they are based on the weather conditions of that variable output power and are uncertain .So, in this paper, first, the amount of solar radiation and wind speed are estimated by neural network according to the figures (7) and (8).

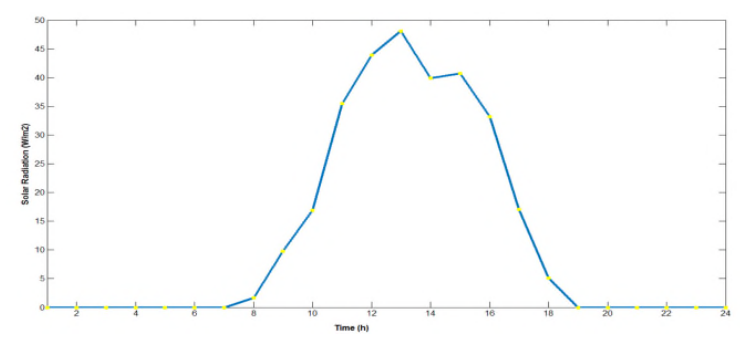

Figure 7: The level of sun radiation 


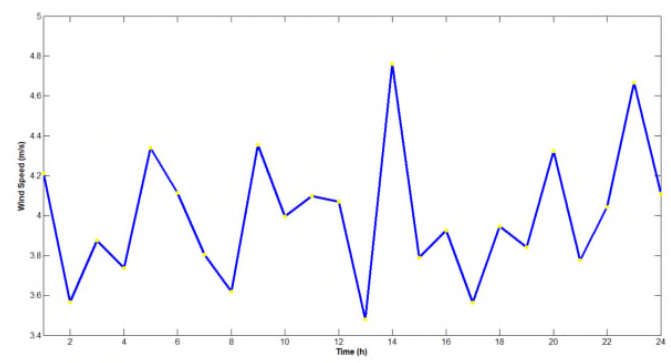

Figure 8: Wind speed changes within a day

The improved genetic algorithm is used to solve the optimization problem. In this study, the number of first generation is 30 chromosomes and the length of each chromosome is equal to 4, because the number of productive resources in the system is 4 , the possibility of power generated by each of these sources should be studied. In the passing of the first iteration to second iteration, the selection process for 70 percent of existing generation has been done and over $20 \%$ of the population, and 10 percent of the elite selection, the migration process will take place. Now, the binary mutations and uniform combination are respectively done on 10 and60 individuals of selected $70 \%$ of the initial population. Now after determining optimization problem, the objective function, constraints and parameters of the problem are studied by using Genetic Algorithm of resource capacity during the three different scenarios. In the first scenario, optimization is only done by the aim of minimizing the investment and operation costs .In the second scenario, the optimization is considered by minimizing the environmental pollution and finally in the third scenario, all three objective functions of cost minimization, pollution and energy losses are considered and the process of optimization is implemented. The results of optimization is given in Table (2).

Table 2: Optimal production capacity in first scenario

\begin{tabular}{|c|c|c|c|}
\hline Resources & Capacity & Costs & Costs ( Dollar ) \\
\hline wind turbines & 113 & $\begin{array}{c}\text { investment and operating } \\
\text { cost }\end{array}$ & 97875 \\
\hline solar panels & 100 & pollution cost & 56080 \\
\hline Bio-diesel generator & 261 & losses cost & 377475 \\
\hline battery & 165 & total & \\
\hline
\end{tabular}

In this scenario, it is observed that the resulting capacity for diesel unit is more than wind and solar units. Because the main purpose in this case is to reduce the cost of investment and operation the system and since diesel generator has lower investment cost rather than other equipment, the capacity of this unit is selected more.

In the second scenario, the first purpose is to determine the optimal capacity of resources to reduce environmental pollution and greenhouse gas emissions. After the implementation of optimization results for the second scenario, Table 3 is as below. 
Table 3: Optimal production capacity in second scenario

\begin{tabular}{|c|c|c|c|}
\hline Resources & Capacity & Costs & Costs ( Dollar ) \\
\hline wind turbines & 135 & $\begin{array}{c}\text { investment and operating } \\
\text { cost }\end{array}$ & 9324290 \\
\hline solar panels & 184 & pollution cost & 37500 \\
\hline Bio-diesel generator & 100 & losses cost & 362725.27 \\
\hline battery & 195 & total & \\
\hline
\end{tabular}

In this scenario, it is observed that the capacity of renewable resources has been selected more than the capacity of bio-diesel generator. Because in this scenario, the main purpose is to reduce the amount of pollution in the environment. Moreover, in this case the solar unit capacity growth has been more than the wind units, because the solar unit has less cost of investment than wind unit.

In third scenario, 3 objectives of the reduction of investment and operation costs, pollution and losses are simultaneously considered by using weighted functions and after the implementation of optimization process, the results of third scenario are given in table (4). In this case, it is observed that both renewable sources and diesel unit have had the capacity increase and a balance point has been obtained compared to the previous two scenarios .In this case the total system cost is reduced compared to previous cases. In addition, due to increased capacity of bio-diesel generator unit, the battery capacity has been decreased. In this case, it is observed that the level of environmental pollution due to increased production of bio-diesel generator unit has been increased.

Table 4: optimal production capacity in the third scenario

\begin{tabular}{|c|c|c|c|}
\hline Resources & Capacity & Costs & Costs ( Dollar ) \\
\hline wind turbines & 110 & $\begin{array}{c}\text { investment and operating } \\
\text { cost }\end{array}$ & 28110 \\
\hline solar panels & 148 & pollution cost & 73875 \\
\hline Bio-diesel generator & 197 & losses cost & 329605 \\
\hline battery & 151 & total & \\
\hline
\end{tabular}

To achieve a better understanding of the issue and the conclusion of the studies, three different cost scenarios are given in Figure (9). The results indicate that the third scenario is optimal. 


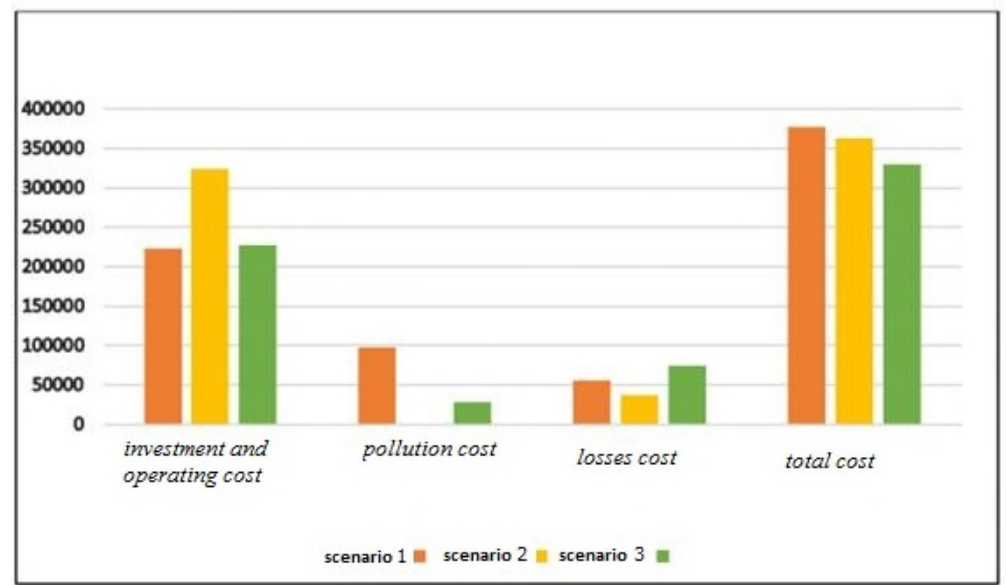

Figure 9: The cost of the system during the three studied scenarios

\section{CONCLUSION}

In general ,based on studies, the presence of renewable energy sources, including solar and wind units in the system reduces the operating costs of the system and the dependence on fossil fuels and diesel units. The selective optimum capacity for renewable units and energy storage is directly related to the amount of initial capital for installation of equipment and increasing the amount of available capital will lead to increase the installed capacity in the system. The use of energy storage such as batteries in the network will cause the storage of surplus wind and solar power can be provided, which this saved power will be injected to network in peak hours and system operating costs will be reduced.

\section{REFRENCES}

[1] D. Kolokotsa, D. Rovas, E. Kosmatopoulos, K. Kalaitzakis, A roadmap towards intelligent net zero- and positive-energy buildings, Sol. Energy 85 (2011), 3067-3084.

[2] D. Kolokotsa, D. Rovas, E. Kosmatopoulos and K. Kalaitzakis, “A Roadmap Toward Intelligent Net Zero- and Positive-Energy Building,” Elsevier, Journal of Solar Energy,vol. 85, no.12, pp. 3067-3084, 2011.

[3] F. Alrashed, M. Asif, "Analysis of critical climate related factors for the application of zero-energy homes in Saudi Arabia," Elsevier, Renewable and Sustainable Energy Reviews, Vol. 41, pp. 1395-1403, 2015.

[4] Y. Lu, S. Wang, Y. Zhao, C. Yan, "Renewable energy system optimization of low/zero energy buildings using single-objective and mult objective optimization methods," Elsevier ,Energy and Buildings, Vol. 89, pp. 61-75, 2015.

[5] L. Wang, J. Gwilliam and Ph. Jones, "Case Study of Zero Energy House Design in UK," Elsevier, Journal of Energy and Building, vol. 41, no.11, pp.1215-1222, 2009.

[6] S. Deng, A. Dalibard, M. Martin, Y.J. Dai, U. Eicker and R.Z. Wang, "Energy Supply Concepts for Zero Energy Residential Building in Humid and Dry Climate," Elsevier ,Journal of Energy Conversion and Management, vol. 52, no.6, pp.2455-2460, 2011.

[7] G.C. Graca, A. Augusto and M.M. Lerer, "Solar Powered Net Zero Energy Houses for Southern Europe: Feasibility Study," Elsevier, Journal of Solar Energy, vol. 86, no.1, pp.634-646, 2012.

[8] M.R. Elkinton, J.G. McGowan and J.F. Manwell, "Wind Power Systems for Net Energy Housing in the United States," Elsevier, Journal of Renewable Energy, vol. 34, no.5, pp.1270-1278, 2009.

[9] S. Rosiek and FJ. Batlles, "Renewable Energy Solutions for Building Cooling, Heating and Power System Installed in an Institutional Building: Case Study in Southern Spain,” Elsevier, Journal of Renewable and Sun stainable Energy Reviews, vol. 26, no.1, pp.147168, 2013. 
Bulletin de la Société Royale des Sciences de Liège, Vol. 85, 2016, p. 140 - 152

[10] D. Jong, K. Kenneth, “Adaptive system design: A Genetic approach,” IEEE Trans. on Systems, Man and Cybernetics, vol. 10, no. $9,1980$. 